\title{
Trends in Carbon Dioxide Capture and Conversion
}

\author{
José A. O. Chagas, ${ }^{a}$ Aryane A. Marciniak ${ }^{b}$ and Claudio J. A. Mota ${ }^{\circledR, a, b, c}$ \\ anstituto de Química, Universidade Federal do Rio de Janeiro, Av. Athos da Silveira Ramos 149, \\ CT Bl A, 21941-909 Rio de Janeiro-RJ, Brazil \\ ${ }^{b}$ Escola de Química, Universidade Federal do Rio de Janeiro, Av. Athos da Silveira Ramos 149, \\ CT Bl E, 21941-909 Rio de Janeiro-RJ, Brazil
}

'INCT Energia \& Ambiente, Universidade Federal do Rio de Janeiro, 21941-909 Rio de Janeiro-RJ, Brazil

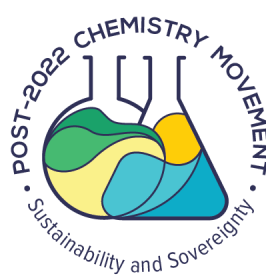

\section{Introduction}

The industrial revolution was based on the use of fossil fuels to run the machines that changed the world. ${ }^{1}$ No one can deny the benefits of the industrial era to our society. The world is now a giant metropolis; travel between countries can take several hours instead of several months with the development of jet airplanes. Food and goods became accessible to the population after the development of synthetic fertilizers and plastics. Life expectancy significantly increased upon the discovery of new drugs to treat diseases. Therefore, life in the $21^{\text {st }}$ century is healthy, wealthy, and more comfortable than it was in the $18^{\text {th }}$ century, in the early stages of the industrial revolution.

Nevertheless, all these accomplishments came with the increase of the $\mathrm{CO}_{2}$ emissions to the atmosphere, together with the devastation of major forest areas in the world.

*e-mail: cmota@iq.ufrj.br

Editor handled this article: Jaísa Fernandes Soares
Hence, Earth is facing fast climate changes that may impact life in the planet, jeopardizing all the benefits brought to the society by the industrial revolution. The nations around the globe are concerned with this situation and many climate agreements have been signed since the end of the $20^{\text {th }}$ century. Today, it is consensual that an increase of up to 1.5 or $2{ }^{\circ} \mathrm{C}$ in the average temperature of the planet must be pursued until the end of the century. This target implies that we must change our energy matrix in the forthcoming years, replacing fossil to renewable energy sources and drastically reducing the carbon emissions.

The recent report of the Intergovernmental Panel on Climate Change (IPCC) ${ }^{2}$ has drawn five possible scenarios or shared socioeconomic pathways (SSP) for the $\mathrm{CO}_{2}$ emissions until the end of the century. SSP1 denotes a sustainable pathway (1). SSP1a also denotes a sustainable pathway, but with higher level of radiative forcing by 2100 . SSP2 denotes an intermediate pathway (2), with emissions decreasing throughout the years, but not reaching zero by 2100. SSP3 and SSP5 refer to unsustainable pathways 
(3 or 5), with fossil sources still sharing important parts of the world's energy matrix. Radiative forcing is defined as the difference between the solar radiation absorbed and radiated to space by Earth in $\mathrm{W} \mathrm{m}^{-2}$. A positive number means that the Earth receives more energy from the sun than it radiates to the space. For the sustainable pathways, the projected radiated forcing by 2100 is within 1.9 and 2.6, whereas for the unsustainable pathways the projected value can be as high as 8.5 .

One can see from Figure 1 that only with sustainable pathways (SSP1 or SSP1a) the world would meet negative $\mathrm{CO}_{2}$ emissions before the end of the century, with high probability of keeping the increase of temperature within 1.5 to $2{ }^{\circ} \mathrm{C}$ relative to the preindustrial era. The intermediate pathway (SSP2) will lead to an estimated increase of at least $2.7^{\circ} \mathrm{C}$, whereas following the unsustainable pathways (SSP3 and SSP5) the temperature of the planet may increase in 3.6 and $4.4{ }^{\circ} \mathrm{C}$, respectively, considering the most favorable estimates. Therefore, it is urgent to act and start decreasing the anthropogenic $\mathrm{CO}_{2}$ emissions during this decade.

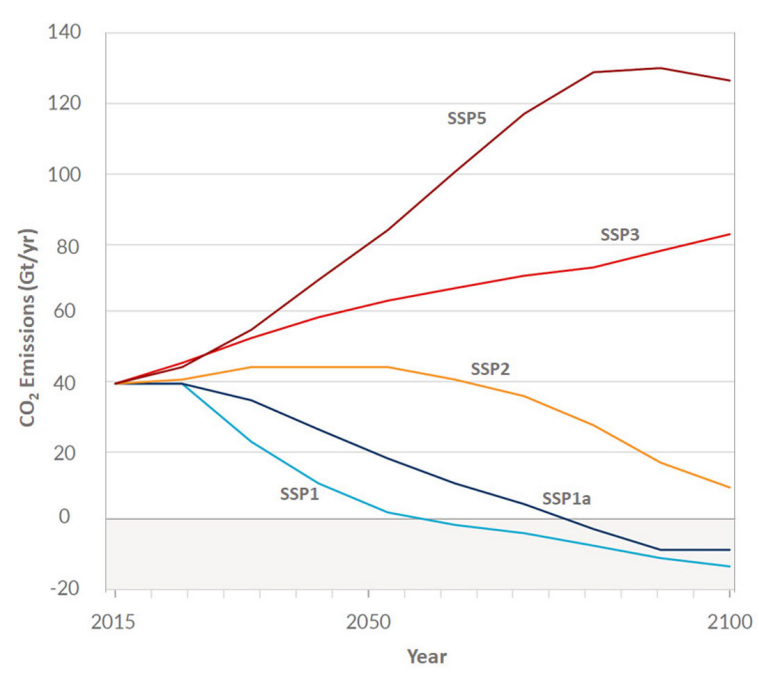

Figure 1. Projected scenarios for the future $\mathrm{CO}_{2}$ emissions (adapted from reference 2).

All organic-derived fuels were originated from photosynthesis, with $\mathrm{CO}_{2}$ and water as feedstocks. Figure 2 depicts the cycles of fossil and bio-derived fuels. Oil and coal were produced upon the geological transformation of organisms that lived on Earth millions of years ago. Time and conditions led to energy-dense molecules like hydrocarbons. The biofuel cycle takes few months, leading to more oxidized, less energy-dense, molecules like sugars and triglycerides. The fossil cycle is beyond the human lifetime. Thus, depletion of the present reserves will lead to shortage of fossil fuels and accumulation of $\mathrm{CO}_{2}$ in the atmosphere. On the other hand, the biofuel cycle is within the human time frame, but yields less energetic molecules and may induce competition for food, which may lead to social problems. Therefore, an anthropogenic fuel cycle must be idealized to circumvent the time frame of the fossil cycle and the energy density and food competition that may be present in the biofuel cycle. This cycle may involve $\mathrm{CO}_{2}$ direct air capture (DAC) for the synthesis of energy-rich molecules. In addition, the cycle must be completed within the time frame of couple of hours (Figure 2).

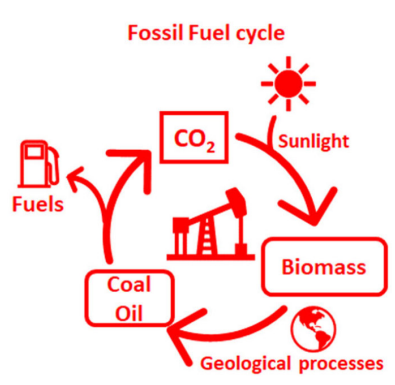

Time frame $=10^{6}-10^{8}$ years

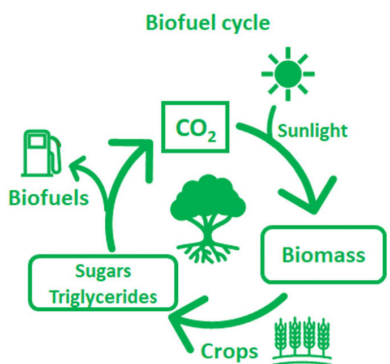

Time frame $=10^{1}-10^{2}$ months
Anthropogenic Fuel cycle

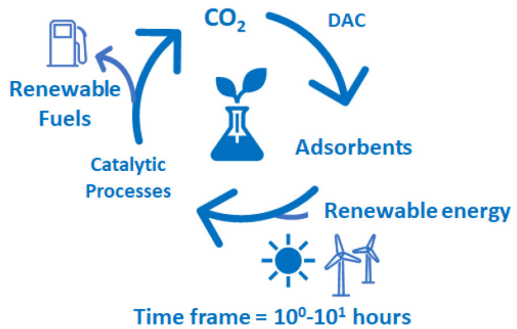

Figure 2. Fossil, bio and anthropogenic fuel cycles.

Carbon dioxide is a linear molecule with zero dipole moment. The $\mathrm{CO}_{2}$ molecule has acidic properties and is considered the anhydride of the carbonic acid. The enthalpy of formation is $-94 \mathrm{kcal} \mathrm{mol}^{-1}$, making $\mathrm{CO}_{2}$ highly stable from the thermodynamic point of view. Figure 3 shows two axles to be considered when $\mathrm{CO}_{2}$ conversion is concerned. ${ }^{3,4}$ Reduction of the oxidation state of the carbon atom requires energy input. Therefore, to go from $\mathrm{CO}_{2}$ (the highest oxidation state) to $\mathrm{CH}_{4}$ (the lowest oxidation state) a significant energy input is required, as methane has an enthalpy of formation around $-18 \mathrm{kcal} \mathrm{mol}^{-1}$. On the other hand, keeping the same oxidation state of the carbon atom, the process may present thermodynamic limitations. Hence, production of organic carbonates, urethanes and urea-derivatives may involve equilibrium issues that must be circumvented in order to achieve high yields. The diagonal axle shows molecules, such as higher hydrocarbons and alcohol, in which the synthesis from $\mathrm{CO}_{2}$ will involve some degree of energy input as well as thermodynamic concerns. 


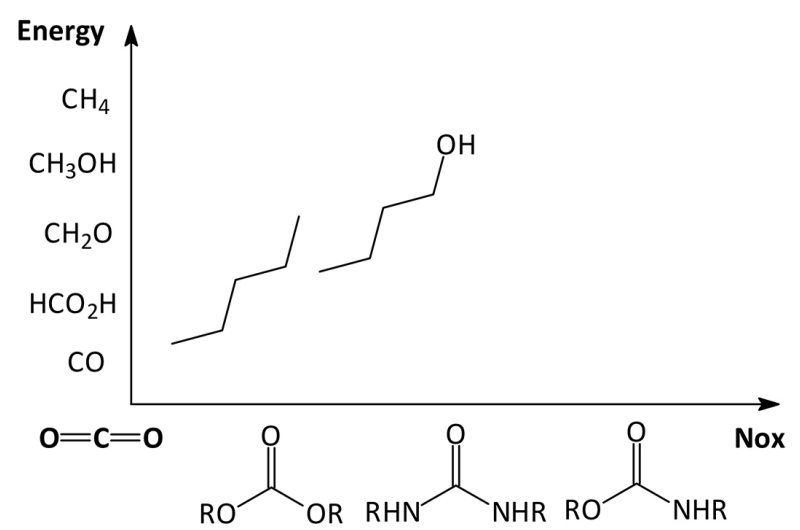

Figure 3. Representation of the energy-oxidation relationship in $\mathrm{CO}_{2}$ transformations (adapted from references 3 and 4).

In this account, we wish to show the recent advances and trends in $\mathrm{CO}_{2}$ capture and conversion. The aim is to focus on functionalized adsorbents, capable of directly capturing $\mathrm{CO}_{2}$ from the air, and converting it to fuels, like methanol and dimethyl ether (DME), as well as chemicals, such as organic carbonates.

\section{2. $\mathrm{CO}_{2}$ Capture by Functionalized Adsorbents}

The direct air capture of $\mathrm{CO}_{2}$ (DAC) is an excellent option for achieving negative emissions in the forthcoming years. ${ }^{5}$ It is dissociated in space and time from existing power plants that capture the $\mathrm{CO}_{2}$ emitted upon the burning of fossil fuels. ${ }^{6}$ The development of materials for capturing $\mathrm{CO}_{2}$ from the air dates back from the $1930 .{ }^{7}$ However, the contextualization in scenarios of climate changes was only considered at the end of the last century. In the last two decades, DAC has grown in importance with the development of functionalized materials that can selectively capture $\mathrm{CO}_{2}$, by chemisorption, from diluted gas streams. ${ }^{8}$ The $\mathrm{CO}_{2}$ adsorption on non-functionalized materials, such as carbons, zeolites and metal-organic frameworks (MOFs), involves physisorption. Thus, less energy is required for releasing the gas from the surface. Nevertheless, as physisorption is not specific, these materials present low $\mathrm{CO}_{2}$ uptake at concentrations similar to atmospheric air, limiting their use in DAC processes. ${ }^{9}$

To deal with these challenges, surface functionalization of porous materials with amino groups has emerged as a viable alternative for DAC..$^{10}$ Materials such as silica, ${ }^{11}$ polymers, ${ }^{12}$ resins, ${ }^{13}$ and nanomaterials ${ }^{14}$ have been chemically or physically modified with linear, branched, or polymeric amines. These adsorbents combine the advantage of high specific area with high affinity for the $\mathrm{CO}_{2}$ molecule, resulting in higher adsorption/desorption rates and selectivity. Therefore, they have been considered the most promising materials for DAC.
Amino-functionalized materials capture $\mathrm{CO}_{2}$ through acid-base reactions. Figure 4 illustrates two proposed mechanisms. In anhydrous conditions, primary and secondary amines can react directly with $\mathrm{CO}_{2}$ leading to the formation of ammonium carbamates or carbamic acid derivatives. ${ }^{15}$ The reaction scheme usually requires two amino groups per $\mathrm{CO}_{2}$ molecule. In wet conditions, tertiary amines catalyze the formation of bicarbonate and carbonate. ${ }^{16}$ The stoichiometry involves $1 \mathrm{~mol}$ of $\mathrm{CO}_{2}$ for each mol of amino group to afford ammonium bicarbonate and carbonate salts.

(a) Anhydrous conditions

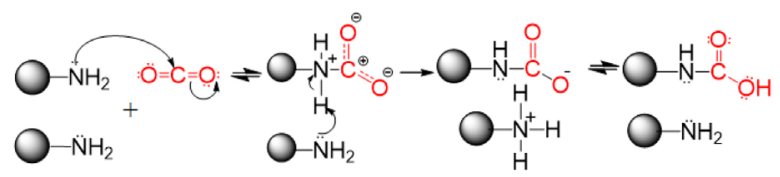

(b) Wet conditions
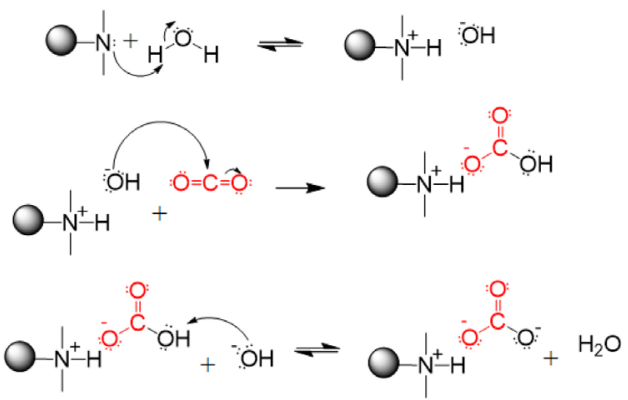

Figure 4. Proposed mechanism of $\mathrm{CO}_{2}$ adsorption on amino-functionalized materials at: (a) anhydrous and (b) wet conditions.

The amino groups have been incorporated on the surface of the solid materials through impregnation, covalent tethering via grafting or covalent tethering via in situ polymerization. ${ }^{11}$ In the impregnation procedure, an amine solution is deposited on the support and the excess of solvent is removed upon drying. ${ }^{17}$ In covalent tethering procedures, the amines are covalently anchored on the support via grafting with an amino-siloxane reagent or other reactions that lead to polymerization. ${ }^{18}$ Figure 5 shows the three main methods for preparing amino-functionalized adsorbents for application in DAC processes.

Several amino compounds, such as monoethanolamine (MEA), tetraethylenepentamine (TEPA), and pentaethylenehexamine (PEHA) have been impregnated on porous supports (Figure 6). Although impregnated solids present high adsorption capacities at low concentrations of $\mathrm{CO}_{2}$, the weak interaction between the support and the amino compounds can result in loss of functionalization during the adsorption/desorption cycles, which involves temperature and pressure swing. Branched polyethyleneimine (PEI) 


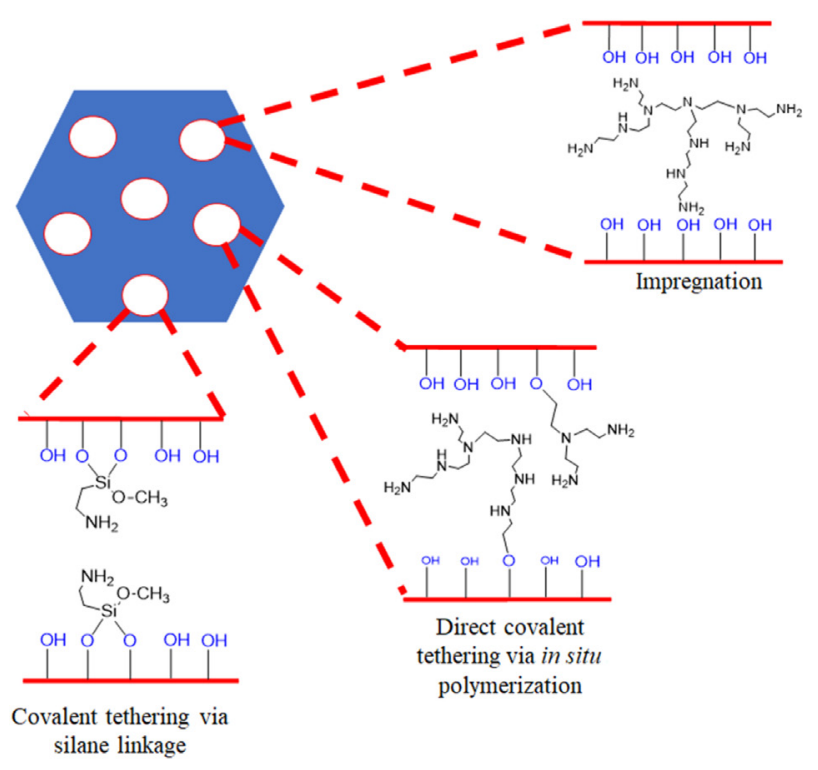

Figure 5. Pictorial representation of different amino functionalization procedures of materials.

has often being used in DAC processes because of its high density of amino functionalization and low vapor pressure under the adsorption/desorption conditions.

Choi et al. ${ }^{19}$ were the first to report the use of commercial silica impregnated with PEI to capture $\mathrm{CO}_{2}$ from the air. The functionalized silica showed $\mathrm{CO}_{2}$ adsorption capacity of $2.36 \mathrm{mmol} \mathrm{g}^{-1}$ under simulated ambient air conditions. However, the adsorption capacity is reduced to $30 \%$ of the initial value after four cycles.

Goeppert et al. ${ }^{20}$ used PEI-impregnated fumed silica for DAC simulated conditions. Impregnation with 33 and $50 \%$ of PEI produced materials with $\mathrm{CO}_{2}$ uptakes of 1.18 and $1.71 \mathrm{mmol} \mathrm{g}^{-1}$ at $25^{\circ} \mathrm{C}$, respectively. These materials presented improved adsorption kinetics in dry and wet conditions, being superior to zeolites, which have poor performance in humid conditions. Wang et al. ${ }^{21}$ studied SBA-15 (Santa Barbara amorphous-15) impregnated with $50 \%$ of PEI for simulated DAC process. They observed $\mathrm{CO}_{2}$ uptake of $0.51 \mathrm{mmol} \mathrm{g}^{-1}$. Other supports such as alumina ${ }^{22}$ and silica fiber ${ }^{23}$ can also be used for PEI impregnation, but usually show lower $\mathrm{CO}_{2}$ adsorption capacities. The main benefit is the high stability in humid and anhydrous conditions.

Amino-impregnated mesoporous supports present some limitations. These materials may present pore restrictions that prevent high loadings of the amine. Another point is associated with the gas transport process, considering that the pore size and amine loading limit the diffusional kinetics. To address these drawbacks, materials with bimodal pore systems are promising candidates. Recently, Kwon et al. ${ }^{24}$ synthesized a hierarchical silica structure impregnated with PEI, using a double template method, and evaluated the performance under DAC conditions. The adsorption capacity was $2.6 \mathrm{mmol} \mathrm{g} \mathrm{g}^{-1}$ under anhydrous condition and $3.4 \mathrm{mmol} \mathrm{g}^{-1}$ under humid conditions.

Aminopropyl siloxanes (APS) and diethylenetriamine (DT) (Figure 7) are the most used feedstocks for grafting amino functionality on porous materials, such as MCM-41 (Mobil composition of matter No. 41). The main advantage is the high stability during several adsorption/desorption cycles, but the major drawback is the lower adsorption capacity compared with the impregnated materials. ${ }^{25}$ Belmabkhout et al..$^{26}$ investigated MCM-41 materials<smiles>NCCO</smiles>

Monoethanolamine<smiles>NCCNCCNCCNCCN</smiles>

Tetraethylenepentamine<smiles>NCCNCCNCCNCCNCCN</smiles><smiles>NCCNCCN(CCN)CCN(CCNCCN)CCNCCN</smiles>

Polyethyleneimine

Figure 6. Structures of the most common amines used in the functionalization of solid supports for direct air capture.

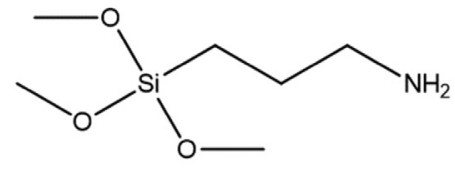

APS<smiles>NCCNCCN</smiles>

DT

Figure 7. Structure of APS and DT amino-compounds used for functionalization of porous materials. 
functionalized with DT for DAC simulated processes, observing a $\mathrm{CO}_{2}$ adsorption capacity of $0.98 \mathrm{mmol} \mathrm{g}^{-1}$ at $25^{\circ} \mathrm{C}$, with high selectivity.

A new class of amino-functionalized materials, described as hyperbranched amino silica (HAS), can be produced by in situ polymerization on SBA- $15 .{ }^{27}$ These materials have adsorption capacities in the range of 0.2 to $1.5 \mathrm{mmol} \mathrm{g}^{-1}$ and exhibit excellent stability during adsorption/desorption cycles. Other materials such as polymers, ion exchange resins, and carbons have been functionalized with amino groups and studied in the direct air capture of $\mathrm{CO}_{2}$. Lu et al. ${ }^{28}$ developed aminofunctionalized porous polymers with specific area of $4023 \mathrm{~m}^{2} \mathrm{~g} \mathrm{~g}^{-1}$ and $\mathrm{CO}_{2}$ adsorption capacity of $1.04 \mathrm{mmol} \mathrm{g}^{-1}$ under DAC conditions. PEI impregnated ion-exchange resin presents $\mathrm{CO}_{2}$ adsorption of $2.26 \mathrm{mmol} \mathrm{g}{ }^{-1}$ at $25^{\circ} \mathrm{C} .{ }^{29}$

Ethylenediamine-functionalized MOFs have also been studied for $\mathrm{CO}_{2}$ direct air capture. ${ }^{30}$ Adsorption capacities as high as $3.89 \mathrm{mmol} \mathrm{g}^{-1}$ under DAC conditions have been observed, ${ }^{31}$ but the main problem is the stability of the materials during various adsorption/desorption cycles. Nanomaterials are another potential class of functionalized adsorbents for DAC processes. Cellulose nanofibers modified with phthalimide showed $\mathrm{CO}_{2}$ uptake of $5.2 \mathrm{mmol} \mathrm{g}^{-1}$ under DAC conditions. ${ }^{32}$ Assessments of other properties that may affect the capture process are still needed, such as performance under real conditions and detailed analysis of the kinetic process associated with adsorption/desorption cycles.

Our group has focused on a different approach for obtaining functionalized materials for $\mathrm{CO}_{2}$ capture. We have exploited the hydrothermal carbonization of chitosan, a natural nitrogen-containing polysaccharide..$^{33}$ Table 1 shows the nitrogen content, surface area and $\mathrm{CO}_{2}$ uptake of different carbonized chitosan materials. One can see that upon hydrothermal carbonization the nitrogen content and surface area does not change, but the uptake of pure $\mathrm{CO}_{2}$ at 1 bar and $25^{\circ} \mathrm{C}$ increased by more than four folds relative to the parent chitosan. The combination of chitosan hydrothermal carbonization followed by calcination in the presence of $\mathrm{K}_{2} \mathrm{CO}_{3}$ significantly increases the surface area, while maintaining a high degree of functionalization of the material. The $\mathrm{CO}_{2}$ uptake was increased by 10 folds, showing the potential of these functionalized materials for DAC, although the adsorption kinetics is significant slower, probably due to the lower concentration of adsorption sites per surface area.

\section{Hydrogenation to Methanol and DME}

Methanol is an important commodity mostly used in the manufacture of resins, plastics, adhesives, and paints, as well as in the production of biodiesel. ${ }^{34}$ The so-called "Methanol Economy" was proposed by Olah et al. ${ }^{35}$ as a sustainable alternative to replace fossil fuels, when produced from $\mathrm{CO}_{2}$ and $\mathrm{H}_{2}$ obtained from renewable sources.

The main current process of methanol synthesis involves natural gas reforming, followed by reaction of the produced syngas over $\mathrm{Cu} . \mathrm{ZnO} \cdot \mathrm{Al}_{2} \mathrm{O}_{3}$ catalysts. The overall process is energy-intensive, being endothermic by $27 \mathrm{kcal} \mathrm{mol}^{-1}$ (Scheme 1). The $\mathrm{CO}_{2}$ hydrogenation to methanol is exothermic but requires an additional hydrogen molecule and produces water as byproduct. ${ }^{36}$ Although there is a commercial plant in Iceland that produces methanol using this route, ${ }^{37}$ the process is still incipient and there are still many challenges to be overcame. Besides $\mathrm{CO}_{2}$ capture, the source of hydrogen and improved catalyst formulations ${ }^{38}$ are among the main issues to be addressed for the widespread use of this process.

$$
\begin{array}{ll}
\text { Route from natural gas } & \\
\mathrm{CH}_{4}+\mathrm{H}_{2} \mathrm{O} \longrightarrow \mathrm{CO}+3 \mathrm{H}_{2} & \Delta \mathrm{H}=+49 \mathrm{kcal} \mathrm{mol}^{-1} \\
\mathrm{CO}+2 \mathrm{H}_{2} \longrightarrow \mathrm{CH}_{3} \mathrm{OH} & \Delta \mathrm{H}=-22 \mathrm{kcal} \mathrm{mol}^{-1}
\end{array}
$$

Route from $\mathrm{CO}_{2}$

$$
\mathrm{CO}_{2}+3 \mathrm{H}_{2} \rightleftharpoons \mathrm{CH}_{3} \mathrm{OH}+\mathrm{H}_{2} \mathrm{O} \quad \Delta \mathrm{H}=-12 \mathrm{kcal} \mathrm{mol}^{-1}
$$

Scheme 1. Pathways form natural gas and $\mathrm{CO}_{2}$ for the synthesis of methanol.

The traditional $\mathrm{Cu} . \mathrm{ZnO} \cdot \mathrm{Al}_{2} \mathrm{O}_{3}$ catalyst is active in the hydrogenation of $\mathrm{CO}_{2}$ to methanol. ${ }^{4}$ However, the best

Table 1. Functionalization, surface area and $\mathrm{CO}_{2}$ uptake of chitosan-derived materials

\begin{tabular}{lcccc}
\hline Material & $\mathrm{N} / \mathrm{wt} . \%$ & Area $/\left(\mathrm{m}^{2} \mathrm{~g}^{-1}\right)$ & $\mathrm{CO}_{2}$ uptake $^{\mathrm{a}} /\left(\mathrm{mmol} \mathrm{g}^{-1}\right)$ & $\mathrm{Kinetic} \mathrm{constant}^{\mathrm{b}} /\left(\mathrm{g} \mathrm{mmol}^{-1} \mathrm{~min}^{-1}\right)$ \\
\hline Chitosan & 7.3 & 2.2 & 0.1 & 15.3 \\
CHIT-HTC-24 $^{\mathrm{c}}$ & 7.3 & 1.8 & 0.3 & 3.7 \\
CHIT-HTC-48 $^{\mathrm{c}}$ & 7.5 & 2.6 & 0.45 & 3.2 \\
CHIT-HTC-48-CO3-700 $^{\mathrm{d}}$ & 5.6 & 2262 & 4.5 & 0.2 \\
\hline
\end{tabular}

${ }^{a}$ Measured at 1 bar of $\mathrm{CO}_{2}$ at $25^{\circ} \mathrm{C}$; ${ }^{\text {b }}{ }^{\text {nd }}$ order kinetic constant $(\mathrm{k})$ taken from the adsorption isotherm at 1 bar of $\mathrm{CO}_{2}$ at $25^{\circ} \mathrm{C}$; ${ }^{\text {chydrothermal carbonized }}$

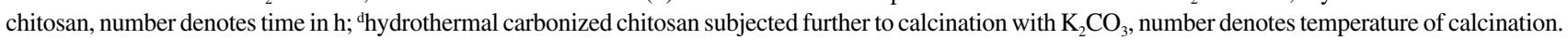


performance is observed at $270{ }^{\circ} \mathrm{C}$, where the equilibrium of the reaction is less favorable (Figure 8). At lower temperatures, the methanol yield is significantly below the thermodynamic threshold due to the activity of the catalyst. Above $270{ }^{\circ} \mathrm{C}$, reverse water gas shift becomes important, and affects the methanol yield. Thus, the design of new catalyst formulation, able to work near the thermodynamic limits at lower temperatures, is highly desired.

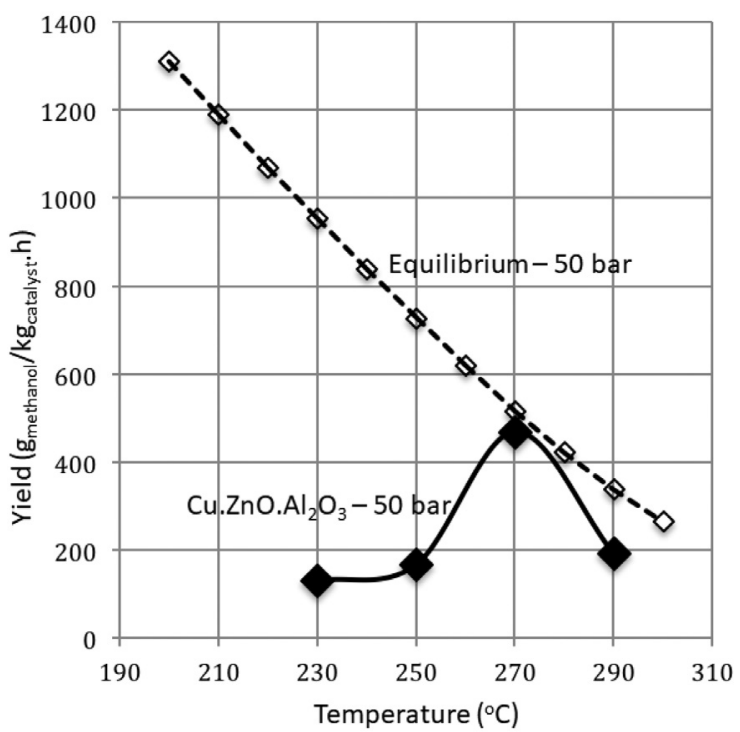

Figure 8. Methanol yield on the hydrogenation of $\mathrm{CO}_{2}$ over $\mathrm{Cu} . \mathrm{ZnO} \cdot \mathrm{Al}_{2} \mathrm{O}_{3}$ catalyst at different temperatures.

Many metal oxides, such as chromium, rare earth elements, gallium, and zirconium can be used together or replacing $\mathrm{Al}_{2} \mathrm{O}_{3}$ in the traditional $\mathrm{Cu} . \mathrm{ZnO}$ catalyst. ${ }^{39} \mathrm{ZrO}_{2}$ is one of the main promoters of the methanol synthesis catalysts and may improve the thermal stability, minimizing the sintering of the $\mathrm{Cu}$ particles. ${ }^{40}$ Lanthanum oxide can increase the $\mathrm{Cu}$ surface area. ${ }^{41}$ There are also studies on the use of different families of catalysts for $\mathrm{CO}_{2}$ hydrogenation. For instance, catalytic systems using $\operatorname{In}_{2} \mathrm{O}_{3}$ have shown high activity and selectivity for $\mathrm{CO}_{2}$ hydrogenation to methanol. ${ }^{42}$ The creation of oxygen vacancies seems to be important, and it is possible to increase the number of active vacancies using $\mathrm{ZrO}_{2}$ as promoter of $\mathrm{In}_{2} \mathrm{O}_{3}$ catalysts. The main drawback for the widespread use of $\operatorname{In}_{2} \mathrm{O}_{3}$ as catalyst in the hydrogenation of $\mathrm{CO}_{2}$ to methanol is its limited availability. Indium is an endangered element, ${ }^{43}$ with mineral reserves being scarce all over the world.

The preparation of the catalyst precursor is of prime importance to produce a good $\mathrm{Cu} . \mathrm{ZnO}$ methanol catalyst. It has been reported ${ }^{44}$ that formation of zincian malachite phase during the aging process is crucial to prepare a high-active catalyst. We have studied the aging of different $\mathrm{Cu} . \mathrm{ZnO}$ catalyst formulations, trying to establish the best conditions to form zincian malachite phases, as shown from the XRD patterns (Figure 9). Promotion with $\mathrm{ZrO}_{2}$ and $\mathrm{MgO}$ led to the formation of the malachite phase at the same aging conditions used for $\mathrm{Al}_{2} \mathrm{O}_{3}$ promotion. On the other hand, $\mathrm{CaO}$ and $\mathrm{BaO}$ promoters did not lead to formation of zincian malachite phases at same aging conditions. As a direct consequence, the textural properties of these two catalyst formulations were significantly worse (Table 2). Therefore, optimizing the aging conditions is of prime importance to prepare good catalysts for methanol synthesis from $\mathrm{CO}_{2}$ and $\mathrm{H}_{2}$.

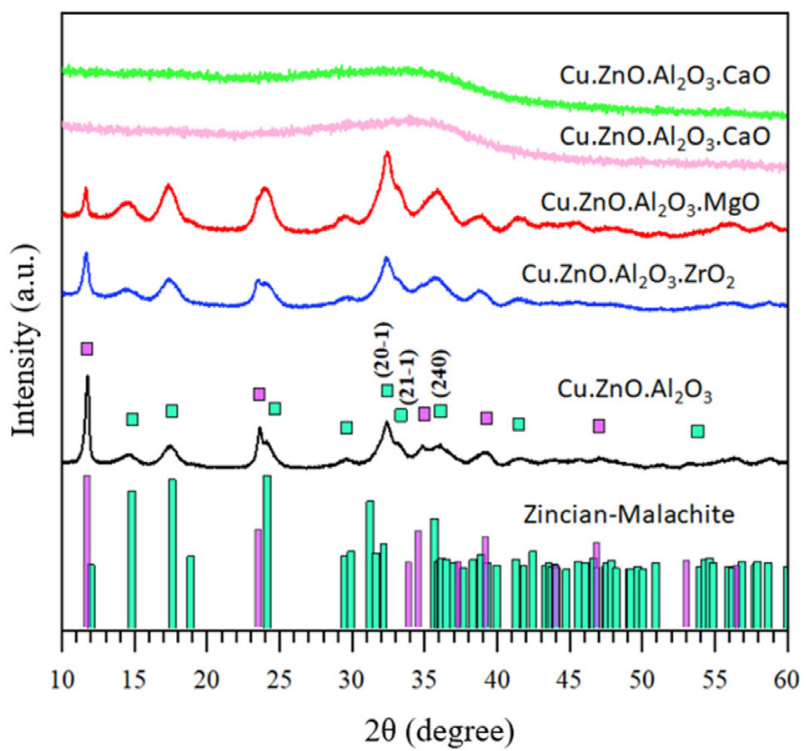

Figure 9. XRD patterns of the catalyst precursors with the different promoters after aging at $60{ }^{\circ} \mathrm{C}$ and $100 \mathrm{~min}$.

Table 2. Textural properties of different catalyst precursors after aging at $60{ }^{\circ} \mathrm{C}$ and $100 \mathrm{~min}$

\begin{tabular}{lc}
\hline Catalyst precursor after aging & Area $/\left(\mathrm{m}^{2} \mathrm{~g}^{-1}\right)$ \\
\hline $\mathrm{Cu} . \mathrm{ZnO} \cdot \mathrm{Al}_{2} \mathrm{O}_{3}$ & 92 \\
Cu. $\mathrm{ZnO} \cdot \mathrm{Al}_{2} \mathrm{O}_{3} \cdot \mathrm{ZrO}_{2}$ & 118 \\
Cu.ZnO. $\mathrm{Al}_{2} \mathrm{O}_{3} \cdot \mathrm{MgO}$ & 119 \\
Cu.ZnO. $\mathrm{Al}_{2} \mathrm{O}_{3} \cdot \mathrm{CaO}$ & 29 \\
Cu. $\mathrm{ZnO} \cdot \mathrm{Al}_{2} \mathrm{O}_{3} \cdot \mathrm{BaO}$ & 30 \\
\hline
\end{tabular}

DME is considered a clean fuel, which can burn without emitting particulate matters and sulfur, used to replace diesel in compression ignition engines due to its high cetane number. ${ }^{45}$ It can be produced by dehydration of methanol over acidic catalysts in the temperature range of 250 to $400{ }^{\circ} \mathrm{C}$ and pressures above 18 bar. $^{46}$ Zeolites, alumina, and mixed metal oxides are among the most traditional acid catalysts used. Tunning the catalyst acidity is important to avoid side reactions, especially formation of hydrocarbons. 
A direct route to DME, from $\mathrm{CO}_{2}$ and $\mathrm{H}_{2}$, can also be envisaged, being a good option to shift the equilibrium of the $\mathrm{CO}_{2}$ hydrogenation, as the methanol formed may be converted to DME (Scheme 2). The process involves bifunctional catalysts, containing a metallic component, usually $\mathrm{Cu} . \mathrm{ZnO}$, supported over an acidic material. ${ }^{47} \mathrm{We}$ have studied ${ }^{48}$ the use of alumina and niobium oxide as support for the direct synthesis of DME from $\mathrm{CO}_{2}$. Higher selectivity to DME can be observed with $\mathrm{Al}_{2} \mathrm{O}_{3}$ as support of the $\mathrm{Cu} . \mathrm{ZnO}$ methanol catalyst, because of its higher acidity compared with niobium oxide. The selectivity to DME can be further improved by modifying the alumina with $\left(\mathrm{NH}_{4}\right)_{2} \mathrm{SiF}_{6}{ }^{49}$ This procedure introduces silicon atoms on the alumina surface producing sites of higher acid strength.

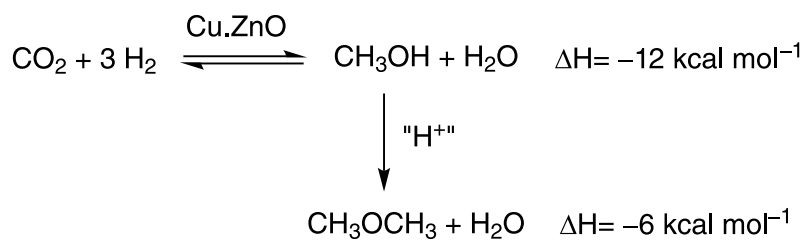

Scheme 2. Direct route of DME production from $\mathrm{CO}_{2}$ using bifunctional catalysts.

There is no industrial plant that produces DME directly from syngas or $\mathrm{CO}_{2}$. Although many academic studies have been reported in the literature, the process requires improvements on catalyst formulation to control hydrogenation and dehydration. Both reactions are exothermic, but the water formed may affect the dispersion of the $\mathrm{Cu}$ particles and the acidity of the support. Thus, improvements on catalyst formulations are still necessary to turn the direct route feasible.

\section{Production of Organic Carbonates}

The conversion of $\mathrm{CO}_{2}$ to organic carbonates has been extensively investigated as a sustainable alternative to produce valuable chemicals. Organic carbonates have wide applications, including monomers for polycarbonates, polar aprotic solvents of low toxicity, electrolytes in lithium ion batteries, green alkylating agents and fuel additives. ${ }^{50}$

Cyclic organic carbonates are generally produced from the reaction of $\mathrm{CO}_{2}$ with epoxides using homogeneous catalytic systems, but the use of heterogeneous systems is gaining importance..$^{51}$ On the other hand, reaction of $\mathrm{CO}_{2}$ with alcohols to afford aliphatic organic carbonate presents thermodynamic limitations. Hence, besides developing active and selective heterogeneous catalytic systems, it is important to find sustainable solutions to shift equilibrium and achieve high yields of the aliphatic carbonate.

\subsection{Cyclic organic carbonates}

The reaction of $\mathrm{CO}_{2}$ with epoxides to afford cyclic organic carbonates does not produce byproducts (Scheme 3). Depending on the experimental conditions, the formed cyclic organic carbonate can undergo in situ polymerization, but this can be kept to a minimum extent if the polycarbonate is not the primary goal. Furthermore, the epoxide is highly reactive compared to other ethers due to the ring tension. The cycloaddition of $\mathrm{CO}_{2}$ to ethylene oxide (EO) is thermodynamically favorable and exothermic $\left(\Delta \mathrm{H}=-34 \mathrm{kcal} \mathrm{mol}^{-1}\right)$, affording ethylene carbonate, a commercially important cyclic organic carbonate.

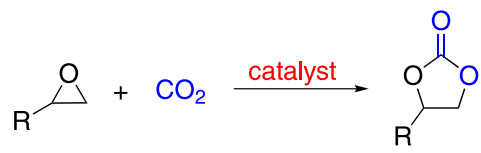

Scheme 3. Cycloaddition of $\mathrm{CO}_{2}$ to epoxide.

Scheme 4 shows the most acceptable mechanistic pathway of the acid-catalyzed reaction of $\mathrm{CO}_{2}$ with epoxides. The ring oxygen atom is firstly activated through interaction with a Lewis acid $\left(\mathrm{A}^{+}\right)$. Then, a nucleophile $\left(\mathrm{X}^{-}\right)$, usually a halide, opens the activated epoxide ring to yield a haloidrin intermediate, which then reacts with $\mathrm{CO}_{2}$ to afford a carboxylate. In the last step, occurs an intramolecular nucleophilic attack, leaving the halide and yielding the cyclic organic carbonate.

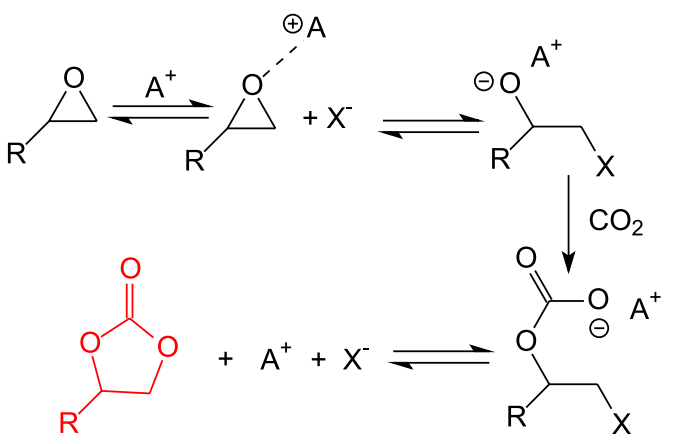

Scheme 4. Mechanistic pathway of the synthesis of cyclic organic carbonates with a Lewis acid $\left(\mathrm{A}^{+}\right)$as catalyst and a nucleophile $\left(\mathrm{X}^{-}\right)$as a co-catalyst.

Most of the catalytic systems used in this reaction are homogeneous. The Lewis acid is usually a metal complex, such as metalloporphyrins, ${ }^{52}$ salen metal complexes, ${ }^{53}$ among others. The nucleophile or co-catalysts normally involve quaternary ammonium salts. ${ }^{54}$ The industrial production of cyclic organic carbonates occurs through homogeneous catalysis, with metal halides being the probable catalyst. ${ }^{55}$ Nevertheless, reusing the catalyst is difficult and has motivated the search for active and 
selective heterogeneous systems. Zeolites ${ }^{56} \mathrm{MOF},{ }^{57}$ silicabased $^{58}$ and metal oxides ${ }^{59}$ have been studied as promising heterogeneous catalysts for the production of cyclic organic carbonates. All present advantages and disadvantages that impair their commercial use up to now.

Our group ${ }^{60}$ has focused on the use of zeolite $Y$ impregnated with metal iodides, as heterogeneous catalysts in the reaction of styrene oxide and $\mathrm{CO}_{2}$ to afford styrene carbonate. The results indicated that KI impregnated on potassium-exchanged zeolite $\mathrm{Y}(\mathrm{KI} / \mathrm{KY})$ is more active than pure KI, although presenting significantly higher epoxide/iodide molar ratios. The conversion and selectivity to styrene carbonate (SC) depends on the amount of iodide impregnated on the zeolite (Table 3). Styrene glycol (SG) is formed as byproduct, probably from hydrolysis of styrene epoxide by some remaining water in the medium.

Table 3. Conversion and selectivity in the reaction of styrene oxide with $\mathrm{CO}_{2}$ over different catalysts. Reaction conditions: $100{ }^{\circ} \mathrm{C}, 50$ bar, $12 \mathrm{~h}$

\begin{tabular}{|c|c|c|c|c|}
\hline \multirow{2}{*}{ Catalyst } & \multirow{2}{*}{$\begin{array}{l}\text { Epoxide/I- } \\
\text { molar ratio }\end{array}$} & \multirow{2}{*}{$\begin{array}{c}\text { Conversion / } \\
\%\end{array}$} & \multicolumn{2}{|c|}{ Selectivity } \\
\hline & & & $\mathrm{SC}^{\mathrm{a}}$ & $\mathrm{SG}^{\mathrm{b}}$ \\
\hline $\mathrm{KI}$ & 15 & 13 & 100 & \\
\hline $\mathrm{KI}(5) / \mathrm{KY}^{\mathrm{c}}$ & 220 & 80 & 87 & 13 \\
\hline $\mathrm{KI}(10) / \mathrm{KY}^{\mathrm{c}}$ & 110 & 94 & 95 & 5 \\
\hline $\mathrm{KI}(13) / \mathrm{KY}^{\mathrm{c}}$ & 86 & 95 & 98 & 2 \\
\hline
\end{tabular}

a Styrene carbonate; ${ }^{\mathrm{b}}$ styrene glycol; ${ }^{\mathrm{C}} \mathrm{KI}$ impregnated on potassiumexchanged zeolite $\mathrm{Y}$, the number in parenthesis stands for the wt.\% of iodide on the zeolite.

Periodic DFT (density functional theory) calculations, using ethylene oxide as model for the epoxide and $\mathrm{LiI} / \mathrm{LiY}$ as model of the zeolite system, corroborated the experimental results, indicating that the rate-determining step is the iodide attack to the epoxide ring. Calculations also indicated the enzyme-like behavior of the zeolites in this reaction. The transition state is perfectly fitted within the pores, upon the participation of two opposing framework aluminum sites. Whereas one site interacts with the impregnated KI, the other activates the epoxide ring, which becomes perfectly aligned with the KI cluster for the opening of the ring (Figure 10).

\subsection{Aliphatic carbonates}

Dimethyl carbonate (DMC) is the most important aliphatic organic carbonate. ${ }^{61}$ The main market for DMC

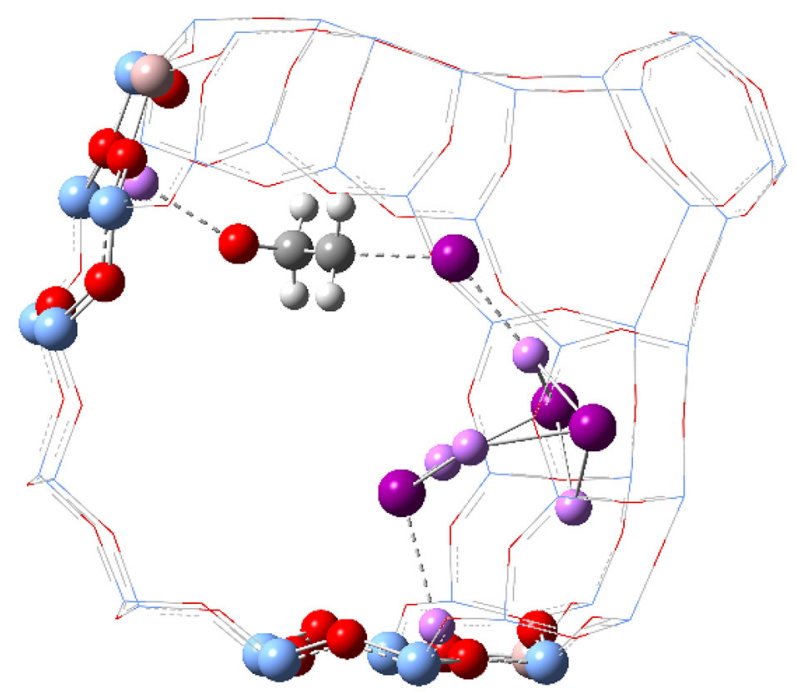

Figure 10. Calculated transition state for the opening of the epoxide ring of ethylene oxide on $\mathrm{LiI} / \mathrm{LiY}$ catalytic system, at periodic boundary conditions with Perdew-Burke-Ernzerhof (PBE) correlation functional.

is Asia, predominantly China and Japan, where DMC is used in the production of polycarbonates. In India, the pharmaceutical industry is responsible for most of the DMC consumption.

Many routes can be used to produce DMC. ${ }^{62-64}$ The current commercial processes are: $(i)$ oxidative carbonylation of methanol over copper-based catalysts; (ii) methylnitrite carbonylation and (iii) transesterification of methanol with ethylene carbonate. ${ }^{65}$ However, they are cost-intensive, also involving hazardous (CO) or explosive (pure $\mathrm{O}_{2}$ ) reagents and, therefore, they cannot be considered completely green or sustainable. On the other hand, direct synthesis from $\mathrm{CO}_{2}$ and methanol has been investigated and considered the most sustainable one (Scheme 5). Nevertheless, it is not favored by thermodynamics and equilibrium must be shifted in order to achieve reasonable yields of DMC.

Many heterogeneous catalysts have been investigated for this reaction, particularly metal oxides. The general, most acceptable, mechanistic scheme involves the adsorption of methanol on acidic sites (A) of the catalyst, followed by interaction with the strong adjacent basic sites (B) to afford adsorbed methoxide $\left(\mathrm{CH}_{3} \mathrm{O}^{-}\right)$and $\mathrm{H}^{+}$ (Figure 11) ${ }^{66}$ Although there is some agreement in the literature about the first step, different proposals have evolved for the next steps, especially the formation of the hemi-carbonate intermediate. Many authors suggest that the

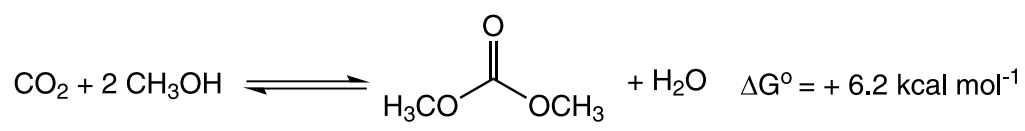

Scheme 5. Direct synthesis of DMC from $\mathrm{CO}_{2}$ and methanol. 
hemi-carbonate is formed from the reaction of $\mathrm{CO}_{2}$ with adsorbed methoxy species, through the general Eley-Rideal catalysis mechanism. ${ }^{67}$

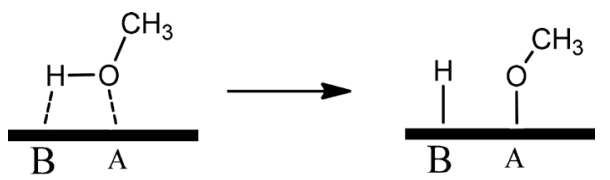

Figure 11. Schematic representation of the formation of methoxy species on the direct synthesis of DMC from $\mathrm{CO}_{2}$ and methanol.

Wada et $a l .{ }^{68}$ showed that the presence of oxygen vacancies on $\mathrm{CeO}_{2}$-type catalysts improves the yield of DMC. The authors proposed a mechanism involving formation of oxygen vacancies on the $\mathrm{CeO}_{2}$ surface, upon reduction with $\mathrm{H}_{2}$, as the first step. Then, the $\mathrm{CO}_{2}$ molecule is adsorbed on these vacancies probably yielding a carbonate intermediate. Methanol is adsorbed on the acid-base sites, as previously discussed, producing the methoxide intermediate. Thus, according to this mechanistic route, at least two adsorbed species are involved.

As $\mathrm{CeO}_{2}$-based catalysts receive considerable interest in the production of $\mathrm{DMC}$ from $\mathrm{CO}_{2}$ and methanol, the role of the oxygen vacancies has been continuously studied. ${ }^{69}$ The vacancies present strong basic properties, ${ }^{70}$ and may adsorb $\mathrm{CO}_{2}$ to yield carbonate and bicarbonate species. Thus, some authors ${ }^{71}$ believe that the rate-determining step is the adsorption and activation of $\mathrm{CO}_{2}$ on the catalyst surface to generate bidentate carbonate.
We recently carried out ${ }^{72}$ a periodical DFT study on the formation of oxygen vacancies as a function of the exposed $\mathrm{CeO}_{2}$ plane, and their role on $\mathrm{CO}_{2}$ adsorption (Figure 12). The results indicated that the exposed (110) plane is more prone to form the vacancies. In addition, it was the only plane that affords carbonate intermediates upon $\mathrm{CO}_{2}$ adsorption. The theoretical results were fully confirmed by experiments with nanostructured $\mathrm{CeO}_{2}$ catalysts.

The direct synthesis of DMC from $\mathrm{CO}_{2}$ and methanol is limited by thermodynamic $\left(\Delta \mathrm{G}^{\circ}=+6.2 \mathrm{kcal} \mathrm{mol}^{-1}\right)$. The reaction is exothermic and increasing temperature does not favor equilibrium toward the products. Hence, to achieve high yields of DMC is necessary to shift equilibrium, which is normally carried out by removal of the water from the medium.

Many non-reactive and reactive dehydrating agents have already been studied. The most commons nonreactive agents are membranes ${ }^{73}$ and molecular sieves. ${ }^{74}$ Nevertheless, since the reaction is usually carried out above $100^{\circ} \mathrm{C}$ and at high pressures, the non-reactive agents are poorly effective in removing water from the medium and shifting equilibrium. On the other hand, reactive dehydrating agents are capable of undergoing hydrolysis with the water produced as byproduct, shifting the chemical equilibrium toward higher DMC yields.

The combination of $\mathrm{CeO}_{2}$ as catalyst and 2-cyanopyridine as dehydrating agent has been reported ${ }^{75}$ to be particularly relevant to achieve high yields of DMC. However, the

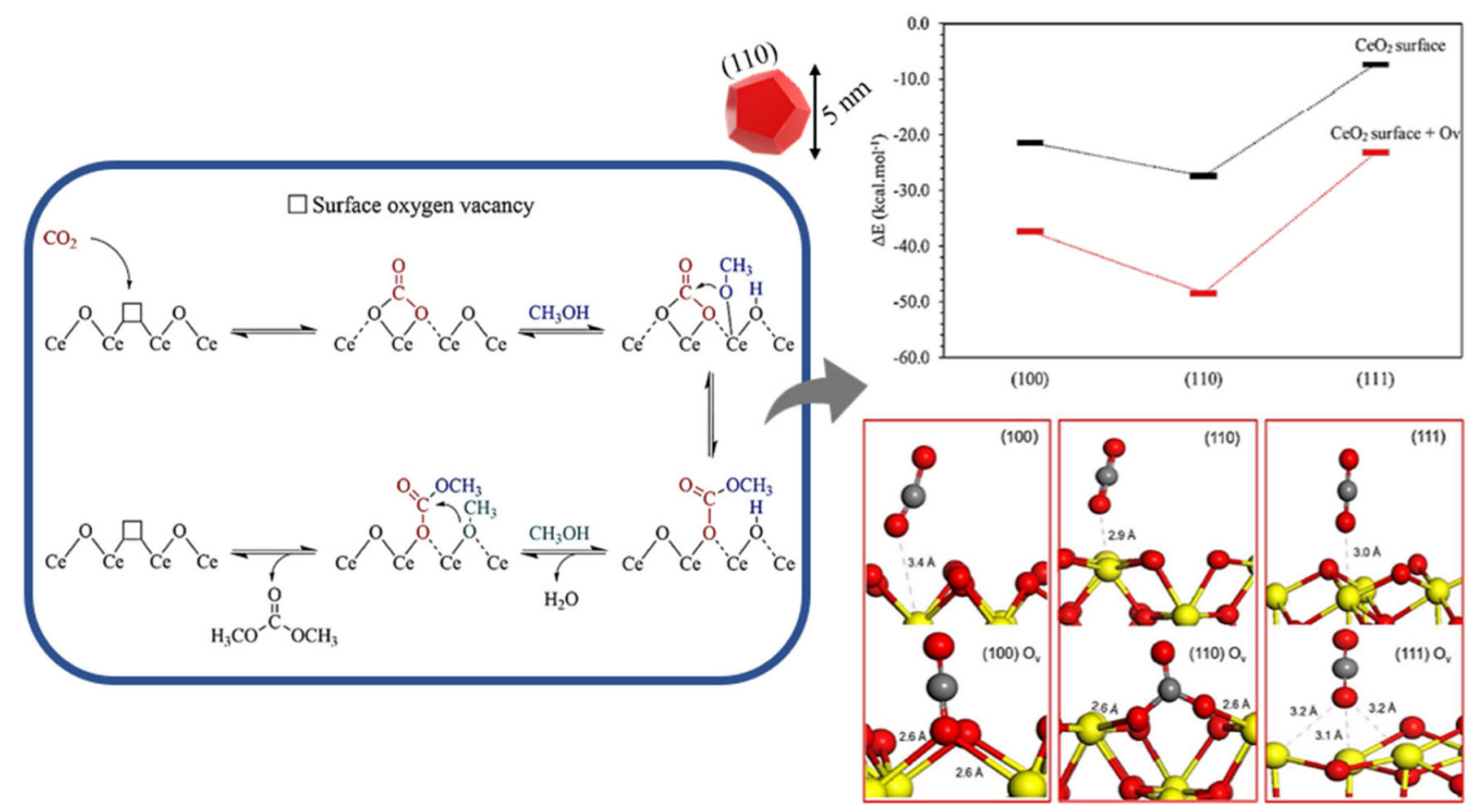

Figure 12. Schematic pathway of DMC synthesis from $\mathrm{CO}_{2}$ and methanol on $\mathrm{CeO}_{2}$ nanoparticle and DFT results showing the $\mathrm{CO}_{2}$ adsorption energy on $\mathrm{CeO}_{2}$ (100), (110) and (111) surface planes with and without oxygen vacancies. Yellow spheres: cerium atoms; red: oxygen atoms and gray: carbon atoms (reproduced from reference 72 with copyright permission from Elsevier). 
hydrolysis of 2-cyanopyridine produces 2-picolinamide and other useless byproducts, making the process unsustainable, because transformation of these side products in the original nitrile is not straightforward. Alternatively, we have used methyl trichloroacetate ${ }^{69,76}$ as a sustainable dehydrating agent (Scheme 6). The ester is hydrolyzed faster than DMC in the reaction medium, producing trichloroacetic acid, which can be further separated and transformed back into the ester, being virtually recycled to the medium.

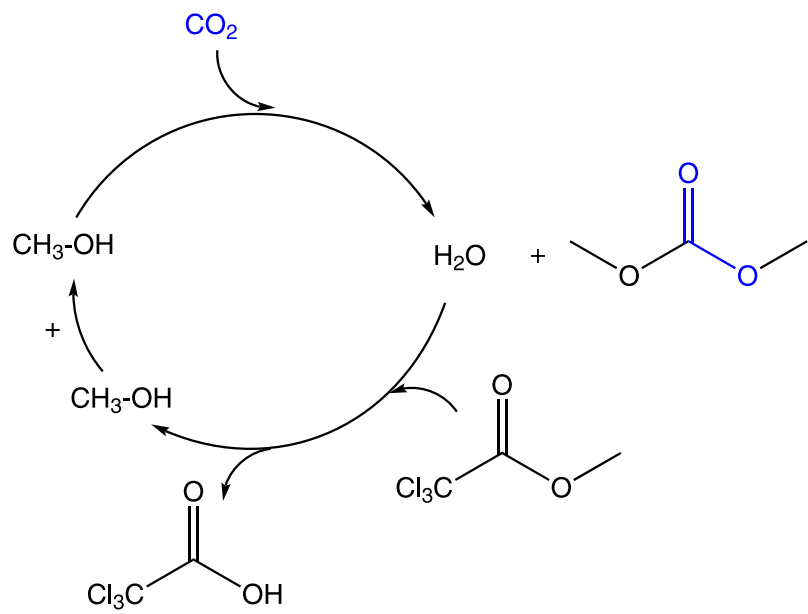

Scheme 6. Use of methyl trichloroacetate as dehydrating agent in the synthesis of DMC from $\mathrm{CO}_{2}$ and methanol. Potential recycling of the trichloroacetic acid.
It also produces higher yields of DMC compared with 2-cyanopyridine ${ }^{69}$ (Table 4).

\section{Future Perspectives in $\mathrm{CO}_{2}$ Capture and Conversion}

There are about 15 pilot plants for direct air capture of $\mathrm{CO}_{2}$ in the world today. ${ }^{77}$ Together, they can capture up to $9 \mathrm{kt}$ of $\mathrm{CO}_{2}$ per year, but the forecast points to about $30 \mathrm{Mt}$ of $\mathrm{CO}_{2}$ captured directly from air by 2030, at a cost of US\$ 90 to US\$200 per ton, or even lower. Hence, the future of $\mathrm{CO}_{2}$ capture indicates the growing importance of DAC.

The design and engineering aspects of DAC units is an important issue that deserves attention. ${ }^{78}$ The system must operate at atmospheric pressure, blowing air through a series of adsorbent beds, to remove water and then capturing $\mathrm{CO}_{2}$ from air. Upon saturation of the adsorbent, the $\mathrm{CO}_{2}$ must be recovered by temperature and pressure swing to be further utilized. Thus, it is necessary to have, at least, two devices in order to operate in continuous mode (Figure 13).

Water is firstly removed on desiccant beds. Then, the water-free air is passed over the functionalized adsorbent beds to capture $\mathrm{CO}_{2}$, exhausting to the atmosphere the air free of carbon dioxide. In order to minimize flow resistance, the beds are normally filled with ceramic monoliths or porous polymers containing the functionalized adsorbents.

Table 4. Catalyst/dehydrating agent system used in the synthesis of $\mathrm{DMC}$ from $\mathrm{CO}_{2}$ and methanol

\begin{tabular}{lccccc}
\hline System & Pressure / bar & Temperature $/{ }^{\circ} \mathrm{C}$ & $\begin{array}{c}\text { DMC yield / } \\
\left(\mathrm{mmol} \mathrm{gat}_{\text {cat }}^{-1}\right)\end{array}$ & DMC selectivity / \% & Reference \\
\hline $\mathrm{CeO}_{2} / 2-\mathrm{CP}^{\mathrm{a}}$ & 50 & 120 & 49 & 100 & 75 \\
$0.02 \mathrm{CuCeO}_{2} / 2-\mathrm{CP}^{\mathrm{b}}$ & 50 & 140 & 84 & 100 & 69 \\
$0.02 \mathrm{CuCeO}_{2} / \mathrm{MTCL}^{\mathrm{c}}$ & 50 & 140 & 208 & 80 & 69 \\
\hline
\end{tabular}

${ }^{\mathrm{a}} \mathrm{CeO}_{2}$ as catalyst and 2-cyanopyridine as dehydrating agent; ${ }^{\mathrm{b}} \mathrm{Cu}$-doped $\mathrm{CeO}_{2}$ as catalyst and 2-cyanopyridine as dehydrating agent; ${ }^{\mathrm{c}} \mathrm{Cu}$-doped $\mathrm{CeO}{ }_{2}$ as catalyst and methyl trichloroacetate as dehydrating agent. DMC: dimethyl carbonate.

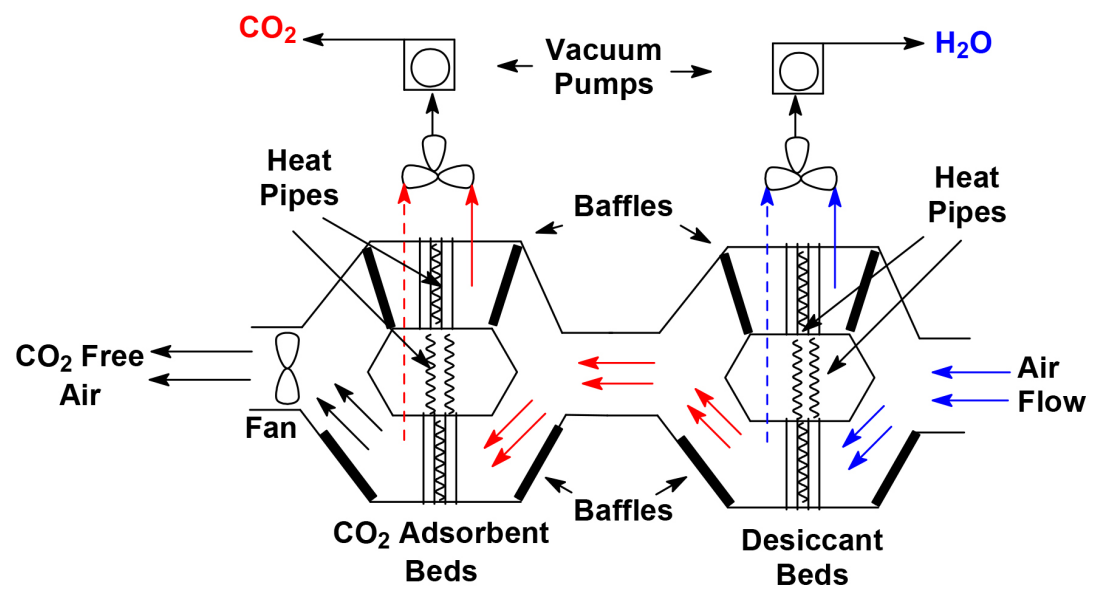

Figure 13. Schematic diagram of a $\mathrm{CO}_{2} \mathrm{DAC}$ device. 
Thus, air may flow with minimum pressure drop between the entrance and the exhaust. It is worth mentioning that to capture $100 \mathrm{~kg}$ of $\mathrm{CO}_{2}$ per day is necessary to blow around 140 thousand $\mathrm{m}^{3}$ of air in the system, considering the present $\mathrm{CO}_{2}$ concentration in the air today.

Ideally, the temperatures for $\mathrm{CO}_{2}$ desorption should be around $100{ }^{\circ} \mathrm{C}$ to avoid excessive heat exchange and decomposition of the functionalized material. Materials based on impregnation of amino compounds gradually loose functionalization through multiple temperature and pressure swings. However, these materials are easily prepared and have low costs compared with amino-grafted ones. On this scenario, the development of materials having amino groups on their structure may pave a way to the future. Therefore, studies on carbonization of nitrogen-containing biomass may fulfill this gap. We have shown that controlled carbonization of chitosan may yield functionalized adsorbents of high surface area and high efficiency for $\mathrm{CO}_{2}$ capture, indicating their potential for DAC.

After being directly captured from air, carbon dioxide can be converted into fuels and chemical. Presently, there are few pilot and demonstration plants for this purpose in the globe. For instance, the $\mathrm{CO}_{2}$ Raw Material from Air $(\mathrm{CORAL})^{79}$ is a German project that captures $\mathrm{CO}_{2}$ from air, using functionalized adsorbents, and produces dimethyl ether via $\mathrm{CO}_{2}$ hydrogenation. Hydrogen is obtained from water electrolysis on what is normally referred as electrofuels $^{80}$ (Figure 14). There are other initiatives on this issue, like the Pro-QR project, ${ }^{81}$ which is a partnership between Brazil and Germany. The aim is to produce aviation fuel of low environmental impact and one of the strategies is the direct capture of $\mathrm{CO}_{2}$ from air, followed by its hydrogenation to hydrocarbons, in the aviation jet fuel range, with hydrogen obtained from water electrolysis using clean energy (solar, wind, hydro, etc).

In fact, the source of hydrogen ${ }^{82}$ is an important point of concern on the synthesis of methanol, DME and hydrocarbons from $\mathrm{CO}_{2}$ directly captured from air. For the complete sustainability of the process, the hydrogen must be mainly produced from water using renewable energy. Today, electrolysis is being considered the best option to produce hydrogen from water. Notwithstanding, the high energy demand, associated with high electric power consumption, and the moderate efficiency of the process motivates the search for other routes, not mentioning the use of wind, solar, geothermal or hydropower as a source of renewable energy. Considering the Brazil scenario, photoelectrocatalysis ${ }^{83}$ and photocatalysis ${ }^{84}$ appears as promising routes for hydrogen production from water, as the country encompasses large areas of sunlight exposure. The main issue related with photocatalytic water splitting is the use visible light. Most of the known photocatalysts are active under UV radiation, which is not abundant on the Earth surface. The use of plasmonic resonance ${ }^{85}$ may revolutionize the technology of water splitting by employing visible light to produce $\mathrm{H}_{2}$.

The search of promoters for the traditional $\mathrm{Cu} . \mathrm{ZnO}$ methanol synthesis catalyst still deserves attention. It is of prime importance to develop catalysts that work at the thermodynamic equilibrium at lower temperatures, to maximize the methanol yield. Exotic catalysts, based on endangered elements, may not present a sustainable solution.

The direct hydrogenation of $\mathrm{CO}_{2}$ to DME present several challenges. Besides the improvements on the metallic function, associated with hydrogenation to methanol, it is necessary to find supports with adequate acidity, to dehydrate the methanol molecule under the same reaction conditions of $\mathrm{CO}_{2}$ hydrogenation.

The production of cyclic organic carbonates with $\mathrm{CO}_{2}$ directly captured from air has been recently reported in the literature. ${ }^{86,87}$ The reaction requires use of highly active metal complex catalysts or plasma-induced conditions. Considering the high added-value of the cyclic organic carbonates, any production route using DAC would be interesting. Nevertheless, the reaction must run near atmospheric pressure, otherwise the costs of compression would surpass the benefits of DAC. Hence, development of highly active catalyst, capable of being reused several times, is of prime importance.

Processes of $\mathrm{CO}_{2}$ direct air capture and conversion will be important to contribute with the climate agreements that project an increase of 1.5 to $2{ }^{\circ} \mathrm{C}$ in the temperature of the planet by the end of this century. Although the concept has already been proven, there are plenty of opportunities to develop new or improved technologies, especially concerning the production of fuels and high-

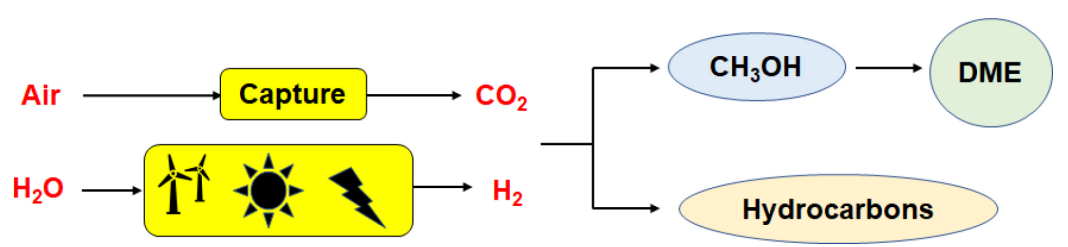

Figure 14. Schematic concept of electrofuels $(\mathrm{PtX})$ from $\mathrm{CO}_{2}$ captured from air and $\mathrm{H}_{2}$ produced from water and renewable energy. 
value chemicals. While the development of advanced materials will play an important role for the production of functionalized adsorbents and highly active and selective catalysts, engineering aspects will also share a relevant role, as DAC devices still require better solutions of heat and mass transfer, as well as integration with the conversion units, which usually work at high pressures.

\section{Acknowledgments}

Authors thank financial support from FAPERJ, CNPq and The Royal Society (UK). J. A. O. C. and A. A. M. thank CAPES for doctoral scholarships.

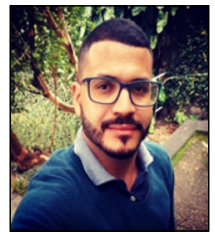

José A. O. Chagas is graduated in Chemistry and student laureate at UFRN and made his doctorate in Chemistry at UFRJ. He is currently an entrepreneur doctor and researcher at UFRJ, developing functionalized materials for $\mathrm{CO}_{2}$ capture and business process modeling. Contemplated by two innovation programs from FAPERJ, Startup Rio, and Entrepreneur Doctor, he is co-creating Carbonair Energy, a technological startup to $\mathrm{CO}_{2}$ capture and utilization. His activities are focused on green chemistry, sustainability, technological innovation, and entrepreneurship.

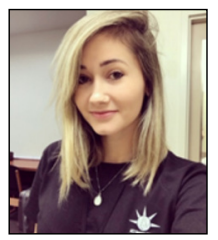

Aryane A. Marciniak is graduated in Chemistry and also made her doctorate studies in Chemistry at UFRJ. She is now a postdoc at UFRJ, working in the direct synthesis of organic carbonates from $\mathrm{CO}_{2}$ and alcohols over heterogeneous catalysts. She spent a short time at the Green Chemistry Centre of Excellence - University of York (England) under supervision of Prof Michael North, developing research focused on $\mathrm{CO}_{2}$ conversion. She matched her doctorate's research with her extra-curricular project, participating in activities of the School of Green Chemistry at UFRJ, and in this area developed many activities related with the promotion of the Green Chemistry principles, focused on chemical education.

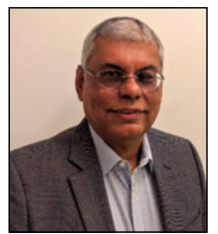

Claudio J. A. Mota is graduated in Chemical Engineering and made his doctorate studies in Chemistry at UFRJ, where he is now full professor and director of the Institute of Chemistry. He authored more than 120 scientific articles, holds 13 patents and is author or editor of three books. He is member of
$S B Q, S B C a t$ and ACS, as well as fellow of the RSC. He is a research fellow of CNPq and State Scientist from FAPERJ. His research interests are focused on green and sustainable processes of biomass catalytic transformation and $\mathrm{CO}_{2}$ capture and conversion to fuels and chemicals.

\section{References}

1. Church, R.; Hist. J. 1996, 39, 535.

2. Intergovernmental Panel on Climate Change (IPCC) In Climate Change 2021: The Physical Science Basis. Contribution of Working Group I to the Sixth Assessment Report of the Intergovernmental Panel on Climate Change; MassonDelmotte, V.; Zhai, P.; Pirani, A.; Connors, S. L.; Péan, C.; Berger, S.; Caud, N.; Chen, Y.; Goldfarb, L.; Gomis, M. I.; Huang, M.; Leitzell, K.; Lonnoy, E.; Matthews, J. B. R.; Maycock, T. K.; Waterfield, T.; Yelekçi, O.; Yu, R.; Zhou, B., eds.; Cambridge University Press: Cambridge, 2021, available at https://www.ipcc.ch/report/ar6/wg1/downloads/report/ IPCC_AR6_WGI_SPM_final.pdf, accessed in January 2022.

3. Gomes, C. N.; Jacquet, O.; Villiers, C.; Thury, P.; Ephritikhine, M.; Cantat, T.; Angew. Chem., Int. Ed. 2012, 51, 187.

4. Mota, C. J. A.; Monteiro, R. S.; Quim. Nova 2013, 36, 1483.

5. McQueen, N.; Gomes, K. V.; McCormick, C.; Blumanthal, K.; Pisciotta, M.; Wilcox, J.; Prog. Energy 2021, 3, 032001.

6. Zeman, F.; Environ. Sci. Technol. 2007, 41, 7558.

7. House, K. Z.; Baclig, A. C.; Ranjanc, M.; van Nierop, E. A.; Wilcox, J.; Herzog, H. J.; PNAS 2011, 108, 20428.

8. Shi, X.; Xiao, H.; Azarabadi, H.; Song, J.; Wu, X.; Chen, X.; Lackner, K. S.; Angew. Chem., Int. Ed. 2020, 59, 6984.

9. Goeppert, A.; Czaun, M.; Prakash, G. K. S.; Olah, G. A.; Energy Environ. Sci. 2012, 5, 7833.

10. dos Santos, T. C.; Bourrelly, S.; Llewellyn, P. L.; Carneiro, J. W. D. M.; Ronconi, C. M.; Phys. Chem. Chem. Phys. 2015, 17, 11095 .

11. Didas, S. A.; Choi, S.; Chaikittisilp, W.; Jones, C. W.; Acc. Chem. Res. 2015, 48, 2680.

12. Zul, S.; Sarwar, I.; Yavuz, C. T.; RSC Adv. 2014, 4, 52263.

13. Parvazinia, M.; Garcia, S.; Maroto-Valer, M.; Chem. Eng. J. 2018, 331, 335.

14. Deng, Y.; Li, J.; Miao, Y.; Izikowitz, D.; Energy Rep. 2021, 7, 3506.

15. Pinto, M. L.; Mafra, L.; Guil, J. M.; Pires, J.; Rocha, J.; Chem. Mater. 2011, 23, 1387.

16. Yin, G.; Liu, Z.; Liu, Q.; Wu, W.; Chem. Eng. J. 2013, 230, 133.

17. Ahmed, S.; Ramli, A.; Yusup, S.; Farooq, M.; Chem. Eng. Res. Des. 2017, 122, 33.

18. Serna-Guerrero, R.; Belmabkhout, Y.; Sayari, A.; Chem. Eng. J. 2010, 161, 173.

19. Choi, S.; Gray, M. L.; Jones, C. W.; ChemSusChem 2011, 4, 628. 
20. Goeppert, A.; Czaun, M.; May, R. B.; Prakash, G. K. S.; Olah, G. A.; Narayanan, S. R.; J. Am. Chem. Soc. 2011, 133, 20164.

21. Wang, X.; Ma, X.; Schwartz, V.; Clark, J. C.; Overbury, S. H.; Zhao, S.; Xu, X.; Song, C.; Phys. Chem. Chem. Phys. 2012, 14,1485 .

22. Chaikittisilp, W.; Kim, H. J.; Jones, C. W.; Energy Fuels 2011 , 25,5528 .

23. Sujan, A. R.; Pang, S. H.; Zhu, G.; Jones, C. W.; Lively, R. P.; ACS Sustainable Chem. Eng. 2019, 7, 5264.

24. Kwon, H. T.; Sakwa-Novak, M. A.; Pang, S. H.; Sujan, A. R.; Ping, E. W.; Jones, C. W.; Chem. Mater. 2019, 31, 5229.

25. Anyanwu, J. T.; Wang, Y.; Yang, R. T.; Ind. Eng. Chem. Res. 2020, 59, 7072.

26. Belmabkhout, Y.; Serna-Guerrero, R.; Sayari, A.; Adsorption 2010, 49, 359 .

27. Choi, S.; Drese, J. H.; Eisenberger, P. M.; Jones, C. W.; Environ. Sci. Technol. 2011, 45, 2420.

28. Lu, W.; Sculley, J. P.; Yuan, D.; Krishna, R.; Wei, Z.; Zhou, H. C.; Angew. Chem., Int. Ed. 2012, 51, 7480.

29. Chen, Z.; Deng, S.; Wei, H.; Wang, B.; Huang, J.; Yu, G.; ACS Appl. Mater. Interfaces 2013, 5, 6937.

30. Lee, W. R.; Hwang, S. Y.; Ryu, D. W.; Lim, K. S.; Han, S. S.; Moon, D.; Choi, J.; Hong, C. S.; Energy Environ. Sci. 2014, 7 , 744.

31. Liao, P. Q.; Chen, X. W.; Liu, S. Y.; Li, X. Y.; Xu, Y. T.; Tang, M.; Rui, Z.; Ji, H.; Zhang, J. P.; Chen, X. M.; Chem. Sci. 2016 , 7, 6528.

32. Sepahvand, S.; Jonoobi, M.; Ashori, A.; Gauvin, F.; Brouwers, H. J. H.; Oksman, K.; Yu, Q.; Carbohydr. Polym. 2020, 230, 115571.

33. Chagas, J. A. O.; Crispim, G. O.; Pinto, B. P.; San Gil, R. A. S.; Mota, C. J. A.; ACS Omega 2020, 5, 29520.

34. Rezende, M. J. C.; de Lima, A. L.; Silva, B. V.; Mota, C. J. A.; Torres, E. A.; da Rocha, G. O.; Cardozo, I. M. M.; Costa, K. P.; Guarieiro, L. L. N.; Pereira, P. A. P.; Martinez, S.; de Andrade, J. B.; J. Braz. Chem. Soc. 2021, 32, 1301.

35. Olah, G. A.; Goeppert, A.; Prakash, G. K. S.; Beyond Oil and Gas: The Methanol Economy, 2nd ed.; Wiley-VCH: Weinheim, 2009.

36. Zhang, X.; Zhang, G.; Song, C.; Guo, X.; Front. Energy Res. 2021, 8, 621119.

37. da Silva, R. J.; Mota, C. J. A. In Carbon Dioxide Utilisation: from Fundamental Discoveries to Production Processes, vol. 2; Styring, P.; North, M., eds; De Grutie: York, UK, 2019, p. 345-360.

38. Zhong, J.; Yang, X.; Wu, Z.; Liang, B.; Huang, Y.; Zhang, T.; Chem. Soc. Rev. 2020, 49, 1385.

39. Wang, W.; Wang, S.; Ma, X.; Gong, J.; Chem. Soc. Rev. 2011, 40, 3703.

40. Dong, X.; Li, F.; Zhao, N.; Xiao, F.; Wang, J.; Tan, Y.; Appl. Catal., B 2016, 191, 8.
41. Goeppert, A.; Czaun, M.; Jones, J. P.; Prakash, J. K. S.; Olah, G. A.; Chem. Soc. Rev. 2014, 43, 7995.

42. Martin, O.; Mart, A. J.; Mondelli, C.; Mitchell, S.; Segawa, T. F.; Hauert, R.; Drouilly, C.; Ferr, D. C.; Ramirez J. P.; Angew. Chem., Int. Ed. 2016, 55, 6261.

43. Rhodes, C. J.; Sci. Prog. 2019, 102, 304.

44. Baltes, C.; Vukojevic, S.; Schuth, F.; J. Catal. 2008, 258, 334. 45. Sorenson, S. C.; J. Eng. Gas Turbines Power 2001, 123, 652.

46. Azizi, Z.; Rezaemanesh, M.; Tohidian, T.; Rahimpour. M. R.; Chem. Eng. Process. 2014, 82, 150.

47. Mota, N.; Ordoñez, E. M.; Pawelec, B.; Fierro, J. L. G.; Navarro, R. M.; Catalysis 2021, 11, 411.

48. Silva, R. J.; Pimentel, A. F.; Monteiro, R. S.; Mota, C. J. A.; J. CO2 Util. 2016, 15, 83.

49. Carvalho, D. F.; Almeida, G. C.; Monteiro, R. S.; Mota, C. J. A.; Energy Fuels 2020, 34, 7269.

50. Schäffner, B.; Schäffner, F.; Verevkin, S. P.; Börner, A.; Chem. Rev. 2010, 110, 4554.

51. Marciniak, A. A.; Lamb, K. J.; Ozorio, L. P.; Mota, C. J. A.; North, M.; Curr. Opin. Green Sustainable Chem. 2020, 26, 100365 .

52. Ema, T.; Miyazaki, Y.; Koyama, S.; Yano, Y.; Sakai, T.; Chem. Commun. 2012, 48, 4489.

53. Lu, X.-B.; Zhang, Y.-J.; Liang, B.; Li, X.; Wang, H.; J. Mol. Catal. A: Chem. 2004, 210, 31.

54. Paddock, R. L.; Hiyama, Y.; McKay, J. M.; Nguyen, S. T.; Tetrahedron Lett. 2004, 45, 2023.

55. Okamoto, H.; Someya, K.; EP1630152A1 2006.

56. Zhang, S.; Jang, M.-S.; Lee, J.; Puthiaraj, P.; Ahn, W.-S.; ACS Sustainable Chem. Eng. 2020, 8, 7078.

57. Song, X.; Wu, Y.; Pan, D.; Zhang, J.; Xu, S.; Gao, L.; Wei, R.; Zhang, J.; Xiao, G.; Appl. Catal., A 2018, 566, 44.

58. Liu, D.; Li, G.; Liu, J.; Yi, Y.; Fuel 2019, 244, 196.

59. Kulal, N.; Vasista, V.; Shanbhag, G. V.; J. CO2 Util. 2019, 33, 434.

60. Ozório, L. P.; da Silva, F. J.; Comerford, J.; North, M.; Mota, C. J. A.; React. Chem. Eng. 2021, 6, 672.

61. Pacheco, M. A.; Marshall, C. L.; Energy Fuels 1997, 11, 2.

62. Bansode, A.; Urakawa, A.; ACS Catal. 2014, 4, 3877.

63. Chiang, C. L.; Lin, K. S.; Yu, S.-H.; Res. Chem. Intermed. 2018 , 44, 3797.

64. Medrano-García, J. D.; Javaloyes-Antón, J.; Vázquez, D.; Ruiz-Femenia, R.; Caballero, J. A.; J. CO2 Util. 2021, 45, 101436.

65. Huang, H.; Samsun, R. C.; Peters, R.; Stolten, D.; Green Chem. 2021, 23, 1734.

66. Di Cosimo, J. I.; Díez, V. K.; Xu, M.; Iglesia, E.; Apesteguía, C. R.; J. Catal. 1998, 178, 499.

67. Capdevila-Cortada, M.; Vilé, G.; Teschner, D.; Pérez-Ramírez, J.; López, N.; Appl. Catal., B 2016, 197, 299.

68. Wada, S.; Oka, K.; Watanabe, K.; Front. Chem. 2013, $1,8$. 
69. Marciniak, A. A.; Alves, O. C.; Appel, L. G.; Mota, C. J. A.; J. Catal. 2019, 371, 88.

70. McFarland, E.; Metiu, H.; Chem. Rev. 2013, 113, 4391.

71. Liu, B.; Li, C.; Zhang, G.; Yao, X.; Chuang, S. S. C.; Li, Z.; ACS Catal. 2018, 8, 10446.

72. Marciniak, A.; Henrique, F.; Lima, A.; Alves, O.; Moreira, C.; Appel, L.; Mota, C. J. A.; Mol. Catal. 2020, 493, 111053.

73. Li, C.; Zhong, S.; Catal. Today 2003, 82, 83.

74. Choi, J.-C.; He, L.-N.; Yasuda, H.; Sakakura, T.; Green Chem. 2002, 4, 230.

75. Honda, M.; Tamura, M.; Nakagawa, Y.; Nakao, K.; Suzuki, K.; Tomishige, K.; J. Catal. 2014, 318, 95.

76. Marciniak, A.; Mota, C. J. A.; ChemistrySelect 2017, 2, 1808.

77. Direct Air Capture; https://www.iea.org/reports/direct-aircapture, accessed in January 2022.

78. Sanz-Pérez, E. S.; Murdock, C. R.; Didas, S. A.; Jones, C. W.; Chem. Rev. 2016, 116, 11840.

79. $\mathrm{CORAL}-\mathrm{CO}_{2}$ Raw Material from Air; https://www.zsw-bw. de/en/projects/regenerative-kraftstoffe/coral-co2-raw-materialfrom-air.html, accessed in January 2022.

80. Millinger, M.; Tafarte, P.; Jordan, M.; Hahn, A.; Meisele, K.; Thrän, D.; Sustainable Energy Fuels 2021, 5, 828.
81. ProQR - Promovendo Combustiveis Alternativos sem Impactos Climáticos; https://www.giz.de/en/worldwide/68382.html, accessed in January 2022.

82. Nazir, H.; Louis, C.; Jose, S.; Prakash, J.; Muthuswamy, N.; Buan, M. E. M.; Flox, C.; Chavan, S.; Shi, X.; Kauranen, P.; Kallio, T.; Maia, G.; Tammeveski, K.; Lymperopoulos, N.; Carcadea, E.; Veziroglu, E.; Iranzo, A.; Kannan, A. M.; Int. J. Hydrogen Energy 2020, 45, 13777.

83. Lianos, P.; Appl. Catal., B 2017, 210, 235.

84. Takata, C. S.; Takata, T.; Domen, K.; Nat. Rev. Mater. 2017, 2 , 17050 .

85. Abouelela, M. M.; Kawamura, G.; Matsuda, A.; J. Cleaner Prod. 2021, 294, 126200.

86. Muthuramalingam, S.; Sankaralingam, M.; Velusamy, M.; Mayilmurugan, R.; Inorg. Chem. 2019, 58, 12975.

87. Guselnikova, O.; Postnikov, P.; Kosina, J.; Kolska, Z.; Trelin, A.; Svorcika, V.; Lyutakov, O.; J. Mater. Chem. A 2021, 9, 8462.

Submitted: October 17, 2021 Published online: February 7, 2022 